\title{
Copolymerization of Ethylene with Isobutylene and Limonene Catalyzed by Titanium Complexes with Various ansa-(Fluorenyl)(alkylamido) Ligand
}

\author{
Yuushou Nakayama ${ }^{1, *}$, Yuuichi Sogo ${ }^{1}$, Ryo Tanaka $^{1}$, Zhengguo Cai $^{1,2}$, \\ and Takeshi Shiono ${ }^{1}$ \\ 1 Department of Applied Chemistry, Graduate School of Engineering, Hiroshima University, Higashi- \\ Hiroshima, Hiroshima 739-8527, Japan \\ 2 State Key Lab of Chemical Fibers \& Polymer Materials, College of Material Science \& Engineering, \\ Donghua University, Shanghai 201620, China \\ *E-mail: yuushou@hiroshima-u.ac.jp
}

\begin{abstract}
A series of titanium complexes bearing ansa-(fluorenyl)(amido) ligands with cyclohexylamido, isopropylamido, and isobutylamido groups were synthesized and their catalytic behaviors for the copolymerization of ethylene with isobutylene were compared with those with cyclododecylamido and tert-butylamido groups. The effects of cocatalyst on the ethylene-isobutylene copolymerization by a titanium complex having ansa(fluorenyl)(cyclododecylamido) ligand were examined. The catalytic activity of the titanium complex for ethylene-limonene copolymerization was also further investigated.
\end{abstract}

Keywords: Copolymerization, ethylene, isobutylene, limonene, titanium, polymerization catalyst. 


\section{Introduction}

ansa-(Cyclopentadienyl)(alkylamido) complexes of titanium, a typical form, $\mathrm{Me}_{2} \mathrm{Si}_{(}\left(\mathrm{C}_{5} \mathrm{Me}_{4}\right)(\mathrm{N} / \mathrm{Bu}) \mathrm{TiMe}_{2}$ (CGC), show excellent performance for the copolymerization of olefinic monomers [1, 2]. Among them, Shaffer and coworkers have reported that an ansa-(cyclopentadienyl)(cyclododecylamido) complex of titanium, $\mathrm{Me}_{2} \mathrm{Si}\left(\mathrm{C}_{5} \mathrm{Me}_{4}\right)\left(\mathrm{N}-c-\mathrm{C}_{12} \mathrm{H}_{23}\right) \mathrm{TiMe}_{2}$ (1), was highly effective for the copolymerization of ethylene (E) with isobutylene (IB) to give alternating copolymers (IB-content $45 \%$ ) [3]. On the other hand, we have reported that the fluorenyl analogues of CGCs, $\mathrm{Me}_{2} \mathrm{Si}\left(\eta^{3}-\mathrm{R}\right)\left(\mathrm{N}^{t} \mathrm{Bu}\right) \mathrm{TiMe}_{2}(\mathrm{R}=$ fluorenyl (2), 2,7${ }^{t} \mathrm{Bu}_{2}$ fluorenyl (3), 3,6- ${ }^{-} \mathrm{Bu}_{2}$ fluorenyl (4)) (Scheme 1), were highly effective for homo- and co-polymerization of higher $\alpha$-olefins and cyclic olefins [4]. Thus, we synthesized a series of titanium complexes with ansa(fluorenyl)(cyclododecylamido) ligands, $\mathrm{Me}_{2} \mathrm{Si}\left(\eta^{3}-\mathrm{R}\right)\left(\mathrm{N}-c-\mathrm{C}_{12} \mathrm{H}_{23}\right) \mathrm{TiMe}_{2}\left(\mathrm{R}=\right.$ fluorenyl (5), 2,7- ${ }^{-} \mathrm{Bu}_{2}$ fluorenyl (6), 3,6- $\mathrm{Bu}_{2}$ fluorenyl (7)), and examined their catalytic behavior for the copolymerization of $\mathrm{E}$ with IB and d-limonene (LM) [5]. In this report, some other titanium complexes (8-10) bearing different secondary and primary alkyl-amido groups were synthesized and their catalytic behaviors for the E-IB copolymerization were examined (Scheme 1). The effects of cocatalysts on the E-IB copolymerization by 6 were also investigated. In addition, the E-LM copolymerization by $\mathbf{6}$ was further studied.

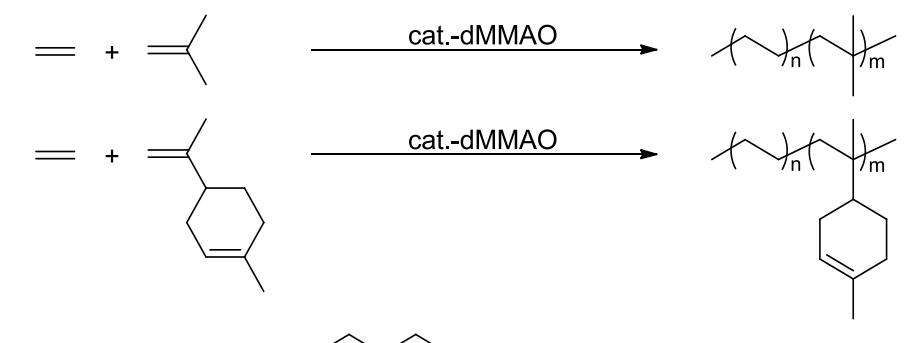

cat:

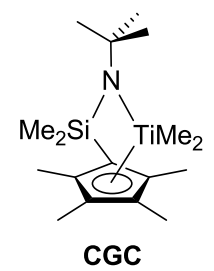

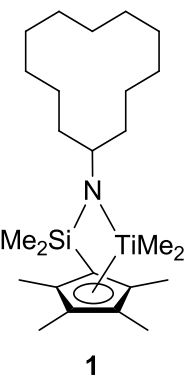

1

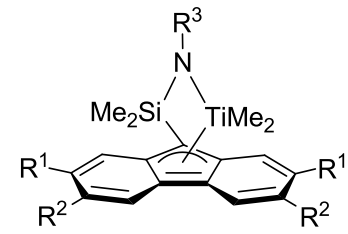

2: $\mathrm{R}^{1}=\mathrm{R}^{2}=\mathrm{H}, \mathrm{R}^{3}={ }^{t} \mathrm{Bu}$

3: $\mathrm{R}^{1}={ }^{t} \mathrm{Bu}, \mathrm{R}^{2}=\mathrm{H}, \mathrm{R}^{3}={ }^{t} \mathrm{Bu}$

4: $R^{1}=H, R^{2}={ }^{t} B u, R^{3}={ }^{t} B u$

5: $R^{1}=R^{2}=H, R^{3}=$ cyclododecyl

6: $\mathrm{R}^{1}={ }^{t} \mathrm{Bu}, \mathrm{R}^{2}=\mathrm{H}, \mathrm{R}^{3}=$ cyclododecyl

7: $\mathrm{R}^{1}=\mathrm{H}, \mathrm{R}^{2}={ }^{t} \mathrm{Bu}, \mathrm{R}^{3}=$ cyclododecyl

8: $R^{1}=R^{2}=H, R^{3}=$ cyclohexyl

9: $R^{1}=R^{2}=H, R^{3}={ }^{i} P r$

10: $R^{1}=R^{2}=H, R^{3}={ }^{i} B u$

Scheme 1.

\section{Experimental}

\subsection{General Remarks}

Because of air and moisture sensitivity of organometallic compounds, all the manipulations were carried out under an atmosphere of pure and dry nitrogen, using standard Schlenk techniques. The complexes 2-7 [57], 9-(chlorodimethylsilyl)fluorene ( $\left.\mathrm{ClSiMe}_{2} \mathrm{Flu}\right)$ [8], and CGC [9] were synthesized according to literatures. MMAO solution in toluene was supplied by TosohFineChem Co. Dried modified methylalminoxane (dMMAO) was prepared by evaporation of the MMAO solution in toluene, followed by repeated redissolving in heptane and evaporation [10].

\subsection{Synthesis of $\mathrm{Me}_{2} \mathrm{Si}$ (fluorenyl)(NH-c- $\left.\mathrm{C}_{6} \mathrm{H}_{11}\right)$}

$n$-BuLi solution $(1.59 \mathrm{M}, 9.4 \mathrm{ml}, 15 \mathrm{mmol})$ in hexane was dropwise added at $0{ }^{\circ} \mathrm{C}$ to a solution of cyclohexylamine $(1.2 \mathrm{~g}, 10 \mathrm{mmol})$ in diethyl ether $(30 \mathrm{ml})$, and the mixture was stirred for $4 \mathrm{~h}$ at r.t. The 
resulting lithium salt was suspended in diethyl ether, and added to a solution of $\mathrm{ClSiMe}_{2} \mathrm{Flu}$ ( $2.5 \mathrm{~g}, 11.2$ mmol) in diethyl ether $(30 \mathrm{ml})$ at $0{ }^{\circ} \mathrm{C}$. The mixture was stirred overnight at r.t. All the volatiles were removed in vacuo and the residue was extracted with hexane. The extract was evaporated in vacuo to give $\mathrm{Me}_{2} \mathrm{Si}$ (fluorenyl) $\left(\mathrm{NH}-c-\mathrm{C}_{6} \mathrm{H}_{11}\right)(2.6 \mathrm{~g}, 8.0 \mathrm{mmol}, 53 \%)$ as an orange liquid. ${ }^{1} \mathrm{H}$ NMR $\left(\mathrm{CDCl}_{3}: 7.26 \mathrm{ppm}\right)$ : $\delta=7.85(\mathrm{~d}, 2 \mathrm{H}, \mathrm{Flu}), 7.58$ (d, 2H, Flu), 7.27-7.35 (m, 4H, Flu), $3.88(\mathrm{~s}, 1 \mathrm{H}, \mathrm{Flu}), 3.05\left(\mathrm{t}, 1 \mathrm{H}, c-\mathrm{C}_{6} \mathrm{H}_{11}\right), 1.90$ (br, $1 \mathrm{H}, \mathrm{NH}), 0.9-1,8\left(\mathrm{~m}, 10 \mathrm{H}, c-\mathrm{C}_{6} \mathrm{H}_{11}\right),-0.07$ (s, 6H, $\left.\mathrm{SiCH}_{3}\right)$.

\subsection{Synthesis of $\mathrm{Me}_{2} \mathrm{Si}$ (fluorenyl)(N-c- $\left.\mathrm{C}_{6} \mathrm{H}_{11}\right) \mathrm{TiMe}_{2}(8)$}

MeLi solution (1.09 M, $30 \mathrm{ml}, 30.5 \mathrm{mmol})$ in diethyl ether was dropwise added at $0{ }^{\circ} \mathrm{C}$ to a solution of $\mathrm{Me}_{2} \mathrm{Si}$ (fluorenyl)(NH- $\left.c-\mathrm{C}_{6} \mathrm{H}_{11}\right)(2.6 \mathrm{~g}, 8.0 \mathrm{mmol})$ in diethyl ether $(60 \mathrm{ml})$, and the mixture was stirred for $4 \mathrm{~h}$ at r.t. The mixture was added to a solution of $\mathrm{TiCl}_{4}(0.88 \mathrm{ml}, 8.0 \mathrm{mmol})$ in hexane $(30 \mathrm{ml})$. After stirring the suspension at r.t. overnight, the solvent was removed in vacuo and the residue was extracted with hexane $(120 \mathrm{ml})$. Then, 3M MeMgBr $(6.7 \mathrm{ml}, 20.2 \mathrm{mmol})$ solution in diethyl ether was added to the extract at r.t. and the mixture was stirred for $1 \mathrm{~h}$. The solvent was removed in vacuo and the residue was extracted with hexane $(100 \mathrm{ml})$. Then the hexane solution was concentrated and cooled to $-30{ }^{\circ} \mathrm{C}$ to give $\mathrm{Me}_{2} \mathrm{Si}$ (fluorenyl) $\left(\mathrm{N}-c-\mathrm{C}_{6} \mathrm{H}_{11}\right) \mathrm{TiMe}_{2}(8)$ as a red powder. ${ }^{1} \mathrm{H}$ NMR $\left(\mathrm{C}_{6} \mathrm{D}_{6}: 7.16 \mathrm{ppm}\right): \delta=8.18(\mathrm{~d}, 2 \mathrm{H}, \mathrm{Flu})$, 7.64 (d, 2H, Flu), 7.40 (t, 2H, Flu), 7.28 (d, 2H, Flu), $2.40\left(\mathrm{~m}, 1 \mathrm{H}, c-\mathrm{C}_{6} \mathrm{H}_{11}\right), 1.1-1.5\left(\mathrm{~m}, 10 \mathrm{H}, c-\mathrm{C}_{6} \mathrm{H}_{11}\right), 0.76$ $\left(\mathrm{s}, 6 \mathrm{H}, \mathrm{SiCH}_{3}\right),-0.51\left(\mathrm{~s}, 6 \mathrm{H}, \mathrm{TiCH}_{3}\right)$.

\subsection{Synthesis of $\mathrm{Me}_{2} \mathrm{Si}$ (fluorenyl)(NHiPr)}

$\mathrm{PrNH}_{2}(1.6 \mathrm{ml}, 18.4 \mathrm{mmol})$ was dropwise added at $0{ }^{\circ} \mathrm{C}$ to a solution of FluSiMe ${ }_{2} \mathrm{Cl}(1.8 \mathrm{~g}, 8.0 \mathrm{mmol})$ in diethyl ether $(45 \mathrm{ml})$, and the mixture was stirred overnight at r.t. All the volatiles were removed in vacuo and the residue was extracted with hexane. The extract was evaporated in vacuo to give $\mathrm{Me}_{2} \mathrm{Si}$ (fluorenyl)(NHPr) $(1.7 \mathrm{~g}, 5.9 \mathrm{mmol}, 74 \%)$ as an orange liquid. ${ }^{1} \mathrm{H}$ NMR $\left(\mathrm{CDCl}_{3}: 7.26 \mathrm{ppm}\right): \delta=7.85$ (d, 2H, Flu), 7.58 (d, 2H, Flu), 7.25-7.36 (m, 4H, Flu), 3.88 (s,1H, Flu), 2.92 (m, 1H, Pr), 1.54 (s, 1H, NH), 0.99 (d, 6H, Pr), -0.07 (s, 6H, $\mathrm{SiCH}_{3}$ ).

\subsection{Synthesis of $\mathrm{Me}_{2} \mathrm{Si}$ (fluorenyl)(NiPr)TiMe (9)}

$\mathrm{Me}_{2} \mathrm{Si}$ (fluorenyl)(NePr)TiMe 2 (9) was synthesized in a similar manner with that for $\mathbf{8}$ by using $\mathrm{Me}_{2} \mathrm{Si}$ (fluorenyl)(NHPr) instead of $\mathrm{Me}_{2} \mathrm{Si}$ (fluorenyl) $\left(\mathrm{NH}-c-\mathrm{C}_{6} \mathrm{H}_{11}\right)$ and obtained as a red powder. ${ }^{1} \mathrm{H}$ NMR $\left(\mathrm{CDCl}_{3}: 7.26 \mathrm{ppm}\right): \delta=8.18$ (d, 2H, Flu), 7.65 (d, 2H, Flu), 7.40 (t, 2H, Flu), $7.29(\mathrm{~m}, 2 \mathrm{H}, \mathrm{Flu}), 4.71(\mathrm{~m}, 1 \mathrm{H}$, Pr), 1.21 (d, 6H, $\mathrm{Pr}), 0.77$ (s, 6H, $\left.\mathrm{SiCH}_{3}\right),-0.49$ (s, 6H, TiCH 3 ).

\subsection{Synthesis of $\mathrm{Me}_{2} \mathrm{Si}$ (fluorenyl)(NHiBu)}

$\mathrm{Me}_{2} \mathrm{Si}$ (fluorenyl)(NH'Bu) was synthesized in a similar manner with that for $\mathrm{Me}_{2} \mathrm{Si}$ (fluorenyl)(NHiPr) by using ${ }^{3} \mathrm{BuNH}_{2}$ instead of $\mathrm{PrNH}_{2}$ and obtained as an orange liquid $\left(78 \%\right.$ yield). ${ }^{1} \mathrm{H}$ NMR $\left(\mathrm{C}_{6} \mathrm{D}_{6}: 7.16 \mathrm{ppm}\right)$ : $\delta=7.79$ (d, 2H, Flu), 7.63 (d, 2H, Flu), 7.38 (m, 2H, Flu), 7.29 (m, 2H, Flu), 3.85 (s,1H, Flu), 2.22 (d, 2H, $\left.{ }^{i} \mathrm{Bu}\right), 1.77(\mathrm{~m}, 1 \mathrm{H}, \mathrm{Bu}), 0.75(\mathrm{~d}, 6 \mathrm{H}, \mathrm{Bu}),-0.16\left(\mathrm{~s}, 6 \mathrm{H}, \mathrm{SiCH}_{3}\right)$.

\subsection{Synthesis of $\mathrm{Me}_{2} \mathrm{Si}$ (fluorenyl)(NiBu) $\mathrm{TiMe}_{2}(10)$}

$\mathrm{Me}_{2} \mathrm{Si}$ (fluorenyl)(N'Bu)TiMe 2 (10) was synthesized in a similar manner with that for 8 by using $\mathrm{Me}_{2} \mathrm{Si}$ (fluorenyl) $\left(\mathrm{NH} \cdot \mathrm{Bu}\right.$ ) instead of $\mathrm{Me}_{2} \mathrm{Si}$ (fluorenyl) $\left(\mathrm{NH}-c-\mathrm{C}_{6} \mathrm{H}_{11}\right)$ and obtained as a red powder. ${ }^{1} \mathrm{H}$ NMR $\left(\mathrm{CDCl}_{3}: 7.26 \mathrm{ppm}\right): \delta=8.19$ (d, 2H, Flu), 7.66 (d, 2H, Flu), 7.39 (t, 2H, Flu), 7.28 (m, 2H, Flu), $3.74(\mathrm{~d}, 1 \mathrm{H}$, $\left.{ }^{\mathrm{Bu}}\right), 1.72(\mathrm{~m}, 1 \mathrm{H}, \mathrm{Bu}), 0.88\left(\mathrm{~d}, 6 \mathrm{H},{ }^{\mathrm{Bu}}\right), 0.73\left(\mathrm{~s}, 6 \mathrm{H}, \mathrm{SiCH}_{3}\right),-0.48\left(\mathrm{~s}, 6 \mathrm{H}, \mathrm{TiCH}_{3}\right)$.

\subsection{Procedure for the Copolymerization of Ehylene with Isobutylene or Limonene}

A reactor was charged with the prescribed amounts of solvent, dMMAO, ethylene gas, and isobutylene or limonene solution in toluene. Polymerization was started by successive addition of $1 \mathrm{ml}$ solution of catalyst $(20 \mu \mathrm{mol})$. The polymerization was conducted for a given time, and then terminated with acidic methanol. 
The obtained polymers were adequately washed with methanol and dried under vacuum at $60{ }^{\circ} \mathrm{C}$ for $6 \mathrm{~h}$. The comonomer-contents of the resulting copolymers were determined as described in the previous paper [5].

\section{Results and Discussions}

The complexes 8 - 10 were synthesized in a similar procedure reported for $5-7$ [5].

\subsection{Copolymerization of Ethylene with Isobutylene}

The E-IB copolymerizations by $\mathbf{8} \mathbf{- 1 0}$ were performed upon activation with dMMAO, trialkylaluminumfree modified methylaluminoxane. The results are summarized in Table 1, in which those by $\mathbf{1}-\mathbf{7}$ and CGC are also included for comparison [5]. Comparing the E-IB copolymerization by the unsubstituted fluorenyl complexes $(\mathbf{2}, \mathbf{5}$, and $\mathbf{8 - 1 0})$, the activity of isopropylamido complex 9 was comparable to that of tertbutylamido complex $\mathbf{2}$ and lower than that of cyclododecylamido complex $\mathbf{5}$, while the cyclohexylamido and isobutylamido complexes $\mathbf{8}$ and $\mathbf{1 0}$ were less active. The IB-contents of the resulting copolymers obtained by $8-10(29,23$, and $31 \mathrm{~mol} \%$, respectively) were higher than that by $\mathbf{2}(18 \mathrm{~mol} \%)$ but lower than that by $\mathbf{5}(35 \mathrm{~mol} \%)$. Thus, the cyclododecylamido ligand was demonstrated to be the most effective for high activity and high IB-incorporation among those amido groups. Although the reason is not clear yet, we speculate that the cyclododecylamido ligand could suppress the interaction between cationic active species with the cocatalyst-derived counter anion to enhance both activity and IB-incorporation. As already reported, the complex $\mathbf{6}$ bearing cyclododecylamido and 2,7-di-tert-butylfluorenyl ligands exhibited relatively high activity and the highest IB-incorporation (48 $\mathrm{mol} \%$ ) to give E-IB alternating copolymer [5].

Table 1. Copolymerization of ethylene with isobutylene by various catalysts.a)

\begin{tabular}{lccccc}
\hline Run & Catalyst & Activity & $\begin{array}{c}\boldsymbol{M}_{\mathbf{n}} \mathbf{c}^{\mathrm{c})} \\
\times 10^{4}\end{array}$ & $\boldsymbol{M}_{\mathbf{w}} / \boldsymbol{M}_{\mathbf{n}}{ }^{\mathrm{c})}$ & $\begin{array}{c}\text { IB-content } \\
(\mathrm{mol} \%)\end{array}$ \\
\hline 1 & $\mathbf{8}$ & 27 & 11.7 & 1.8 & 29 \\
2 & $\mathbf{9}$ & 126 & 0.3 & 1.6 & 23 \\
3 & $\mathbf{1 0}$ & 29 & 0.4 & 2.5 & 31 \\
$4^{\mathrm{e})}$ & $\mathbf{1}$ & 140 & 1.3 & 2.5 & 45 \\
$5^{\mathrm{f}}$ & $\mathbf{2}$ & 143 & 2.1 & 1.8 & 18 \\
$6^{f)}$ & $\mathbf{3}$ & 349 & 5.9 & 2.0 & 17 \\
$7^{f)}$ & $\mathbf{4}$ & 272 & 6.9 & 2.8 & 10 \\
$8^{\mathrm{f}}$ & $\mathbf{5}$ & 246 & 1.8 & 1.9 & 35 \\
$9^{f)}$ & $\mathbf{6}$ & 257 & 3.2 & 1.7 & 48 \\
$10^{f)}$ & $\mathbf{7}$ & 318 & 2.7 & 1.9 & 38 \\
$11^{\mathrm{f}}$ & $\mathbf{C G C}$ & 58 & 1.9 & 2.0 & 3 \\
\hline
\end{tabular}

a) Polymerization conditions: $\mathrm{Ti}=20$ umol, cocatalyst $=d M M A O, A l / T i=400$, solvent $=$ toluene, total volume $=30$ $\mathrm{mL}, \mathrm{E} / \mathrm{IB}(\mathrm{mol} / \mathrm{mol})=0.18, E=0.32 \mathrm{~mol} / \mathrm{l}(1 \mathrm{~atm}), I B=3 \mathrm{~g}(1.78 \mathrm{~mol} / \mathrm{L})$, temp $=25^{\circ} \mathrm{C}$, time $=5 \mathrm{~min}$. b) Activity $=k g(p o l y)$ mol(Ti $)^{-1} b^{-1}$.c) Number-average molecular weight and molecular weight distribution determined by GPC using polystyrene standard. d) Determined by ${ }^{13} \mathrm{C} N M \mathrm{R}$. e) Cocatalyst $=M A O, A l / T i=100, E=0.34 \mathrm{~atm}, I B=6.3$ mol/l [3, 11].f) Reported in the previous paper [5].

In the E-IB copolymerization by $\mathbf{6}$, the effects of cocatalysts were examined (Table 2). When dMMAO was replaced with normal MMAO (runs 12 and 13), the activity, the molecular weight, and the IB-content were decreased. The free trialkylaluminum $\left(\mathrm{AlR}_{3}\right)$ in MMAO might interact with the catalyst metal center to hamper the coordination of IB and to cause chain transfer. The treatment of MMAO with 2,6-di-tert-butyl4-methylphenol (BHT) extremely enhanced catalytic activity and moderately improved IB-incorporation (runs 14 -16). Although the reason for their high activity is not clear, the BHT should react with free $\mathrm{AlR}_{3}$ to give aluminum aryloxide species, which should have lower ability to interact with the catalyst metal center. The use of borate cocatalyst (run 17) resulted in higher activity and somewhat lower IBincorporation in comparison with dMMAO (run 9). 
Table 2. Copolymerization of ethylene with isobutylene by $\mathbf{6}$ activated with various cocatalysts.a)

\begin{tabular}{|c|c|c|c|c|c|c|}
\hline Run & Cocatalyst & $\begin{array}{r}\text { IB } \\
(g)\end{array}$ & Activity ${ }^{\mathrm{b}}$ & $\begin{array}{l}\boldsymbol{M}_{\mathbf{n}}{ }^{\mathrm{c})} \\
\times 10^{4} \\
\end{array}$ & $M_{\mathrm{w}} / M_{\mathrm{n}}{ }^{\mathrm{c})}$ & $\begin{array}{c}\left.\text { IB-content }^{\mathrm{d}}\right) \\
(\mathrm{mol} \%)\end{array}$ \\
\hline $12^{\mathrm{e})}$ & MMAO & 3.0 & 23 & 0.8 & 3.6 & 35 \\
\hline 13 & MMAO & 1.5 & 72 & 0.9 & 2.8 & 28 \\
\hline 14 & MMAO-BHTf & 3.0 & 3860 & 0.4 & 5.7 & 42 \\
\hline 15 & MMAO-BHTf & 1.5 & 6110 & 0.6 & 4.7 & 40 \\
\hline $16^{\mathrm{g})}$ & MMAO-BHTf & 3.0 & 560 & 1.8 & 2.9 & 45 \\
\hline 17 & {$\left[\mathrm{Ph}_{3} \mathrm{C}\right]\left[\mathrm{B}\left(\mathrm{C}_{6} \mathrm{~F}_{5}\right)_{4}\right] / \mathrm{Al}\left({ }^{(} \mathrm{Bu}\right)_{3}$} & 3.0 & 540 & 1.4 & 2.4 & 42 \\
\hline 9e) & dMMAO & 3.0 & 257 & 3.2 & 1.7 & 48 \\
\hline
\end{tabular}

a) Polymerization conditions: $\mathrm{Ti}=20$ umol, cocatalyst $=d M M A O, A l / \mathrm{Ti}=400$, solvent $=$ toluene, total volume $=30$ $m L, E / I B(\mathrm{~mol} / \mathrm{mol})=0.18, E=0.32 \mathrm{~mol} / \mathrm{l}(1 \mathrm{~atm}), I B=3 \mathrm{~g}(1.78 \mathrm{~mol} / \mathrm{L})$, temp $=25{ }^{\circ} \mathrm{C}$, time $\left.=5 \mathrm{~min} . \mathrm{b}\right)$ Activity $=\operatorname{kg}($ poly $)$ mol(Ti) ${ }^{-1} h^{-1}$. c) Number-average molecular weight and molecular weight distribution determined by GPC using polystyrene standard. d) Determined by ${ }^{13} \mathrm{C} N \mathrm{NMR}$ [3, 11]. e) Reported in the previous paper [5]. f) 1.2 equiv. of BHT to free trialkylaluminum in MMAO was added to MMAO.g) Al/Ti=100.

\subsection{Copolymerization of Ethylene with Limonene}

LM is one of the plant-derived renewable olefinic compounds with methylidene functionality, and its homo- or co-polymers might be interesting as entirely or partially biomass-based polymers. Thus, E-LM copolymerization with $\mathbf{6}$, which showed the highest incorporation of IB in E-IB copolymerization, was further studied (Table 3). It is apparent that LM is inferior in the ability to incorporate in the main chain than IB, possibly due to its bulkiness. As previously reported, the 6-dMMAO system enabled E-LM copolymerization to give E-LM copolymer [5]. With decreasing $\mathrm{E}$ introduction, the LM-contents of the resulting copolymers increased up to ca. $4 \mathrm{~mol} \%$, while the molecular weight decreased (runs 19-21). The effects of polymerization temperature and cocatalyst were newly examined in this study. As a result, the $T_{\mathrm{m}}$ value of the resulting copolymer obtained at $60{ }^{\circ} \mathrm{C}$ (run 22) was similar to that at $25^{\circ} \mathrm{C}$ (run 19). However, its molecular weight distribution obtained at $60{ }^{\circ} \mathrm{C}$ was much broader than those obtained at $25{ }^{\circ} \mathrm{C}$, indicating the formation of multiple active species. When MMAO-BHT was used as a cocatalyst instead of dMMAO, ethylene homopolymer was produced (run 23). Although the reason is not clear, the resulting AlBHT complex could have some negative effect on incorporation of LM. LM homopolymerization did not proceeded by 6-dMMAO (run24).

Table 3. Copolymerization of ethylene with limonene by $\mathbf{6}$ activated with various cocatalysts. ${ }^{\text {a) }}$

\begin{tabular}{|c|c|c|c|c|c|c|c|c|c|}
\hline Run & Cocatalyst & $\begin{array}{c}\mathbf{E}^{\mathrm{b})} \\
(\mathrm{mL})\end{array}$ & $\begin{array}{c}\text { Temp. } \\
\left({ }^{\circ} \mathrm{C}\right)\end{array}$ & $\begin{array}{l}\text { Yield } \\
(\mathrm{g})\end{array}$ & $\begin{array}{c}\left.\boldsymbol{M}_{\mathrm{n}} \mathrm{c}\right) \\
\times \\
10^{4}\end{array}$ & $\left.M_{\mathrm{w}} / M_{\mathrm{n}} \mathrm{c}\right)$ & $\begin{array}{c}\text { LM- } \\
\text { content }^{\mathrm{d})} \\
(\mathrm{mol} \%)\end{array}$ & $\begin{array}{l}\left.\boldsymbol{T}_{\mathrm{m}} \mathrm{e}\right) \\
\left({ }^{\circ} \mathrm{C}\right)\end{array}$ & $\begin{array}{c}\left.\Delta \boldsymbol{H}_{\mathrm{m}}^{\mathrm{e}}\right) \\
(\mathrm{J} / \mathrm{g})\end{array}$ \\
\hline $\left.18^{f, g}\right)$ & dMMAO & 350 & 25 & 0.47 & 5.5 & 2.6 & 0 & 133.7 & 121.0 \\
\hline 19g) & dMMAO & 276 & 25 & 0.16 & 5.7 & 1.5 & 1.1 & 126.2 & 34.1 \\
\hline 20 & dMMAO & 140 & 25 & 0.14 & 1.3 & 10.4 & n.d.h) & 124.3 & 33.8 \\
\hline 21g) & dMMAO & 70 & 25 & 0.11 & 0.8 & 23.8 & 3.9 & 123.8 & 4.4 \\
\hline 22 & dMMAO & 265 & 60 & 0.22 & 4.5 & 7.2 & n.d.h) & 126.8 & 91.0 \\
\hline 23 & MMAO-BHTi) & 300 & 25 & 0.27 & 36.4 & 4.9 & $<0.1$ & 130.4 & 122.0 \\
\hline $24 \mathrm{~g}, \mathrm{j})$ & dMMAO & 0 & 25 & trace & - & - & - & - & - \\
\hline \multicolumn{10}{|c|}{ 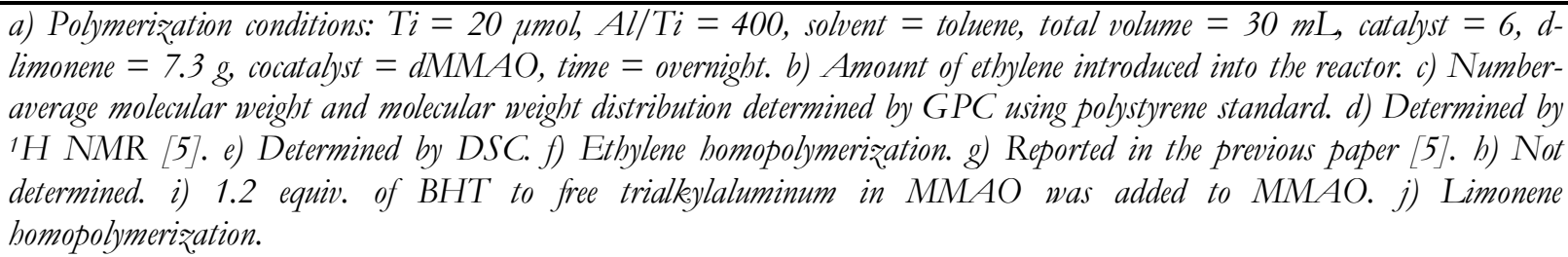 } \\
\hline
\end{tabular}

We also examined copolymerization of $\mathrm{E}$ with $\beta$-pinene, another plant-derived renewable olefinic compound, under the conditions similar to run 19, however, only ethylene homopolymer was obtained. 


\section{Conclusion}

For comparison with the E-IB copolymerization by titanium complexes having ansa(fluorenyl)(cyclododecylamido) ligands (5-7), we examined the E-IB copolymerization by three new complexes with cyclohexylamido (8), isopropylamido (9), and isobutylamido (10) groups. As a result, those complexes 8-10 exhibited lower activities and lower IB-incorporation abilities than those of the corresponding cyclododecylamido complex $\mathbf{5}$. The cocatalyst effect on the E-IB copolymerization with $\mathbf{6}$ was investigated and the use of $\mathrm{dMMAO}$ resulted in the highest IB-incorporation ability among the cocatalysts used in this study. The conditions for E-LM copolymerization by $\mathbf{6}$ was also further studied and the 6-dMMAO system at $25{ }^{\circ} \mathrm{C}$ was the most effective for the E-LM copolymerization among the conditions applied in this study.

\section{Acknowledgement}

This work was financially supported by Advanced Low Carbon Technology Research and Development Program from Japan Science and Technology Agency.

\section{References}

[1] A. L. McKnight and R. M. Waymouth, "Group 4 ansa-cyclopentadienyl-amido catalysts for olefin polymerization," Chem. Rev., vol. 98, pp. 2587-2598, 1998.

[2] H. Braunschweiga and F. M. Breitling, "Constrained geometry complexes-Synthesis and applications," Coord. Chem. Rev., vol. 250, pp. 2691-2720, 2006.

[3] T. D. Shaffer, J. A. M. Canich, and K. R. Squire, "Metallocene-catalyzed copolymerization of ethylene and isobutylene to substantially alternating copolymers," Macromolecules, vol. 31, pp. 5145-5147, 1998.

[4] T. Shiono, "Living polymerization of olefins with ansadimethylsilylene(fluorenyl)(amido)dimethyltitanium-based catalysts," Polym. J., vol. 43, pp.331-351, 2011.

[5] Y. Nakayama, Y. Sogo, Z. Cai, and T. Shiono, "Copolymerization of Ethylene with 1,1-disubstituted olefins catalyzed by ansa-(fluorenyl) (cyclododecylamido)dimethyltitanium complexes," J. Polym. Sci., Part A: Polym. Chem., vol. 51, pp. 1223-1229, 2013.

[6] K. Nishii, H. Hagihara, T. Ikeda, M. Akita, and T. Shiono, "Stereospecific polymerization of propylene with group 4 ansa-fluorenylamidodimethyl complexes," J. Organomet. Chem., vol. 691, pp. 193-201, 2006.

[7] Z. Cai, T. Ikeda, M. Akita, and T. Shiono, "Substituent Effects of tert-butyl groups on fluorenyl ligand in syndiospecific living polymerization of propylene with ansa-fluorenylamidodimethyltitanium complex," Macromolecules, vol. 38, pp. 8135-8139, 2005.

[8] J. Okuda, F. J. Schattenmann, S. Wocadlo, and W. Massa, "Synthesis and characterization of zirconium complexes containing a linked amido-fluorenyl ligand," Organometallics, vol. 14, pp. 789-795, 1995.

[9] D. R. Neithamer, and J. C. Stevens, "Preparation of monocyclopentadienyl metal complex compounds and method of use," WO 9323412, 1993.

[10] H. Hagimoto, T. Shiono, and T. Ikeda, "Living Polymerization of propene with a chelating diamide complex of titanium using dried methylaluminoxane," Macromol. Rapid Commun., vol. 23, pp. 73-76, 2002.

[11] H. Li, L. Li, T. J. Marks, L. Liable-Sands, and A. L. Rheingold, "Catalyst/cocatalyst nuclearity effects in single-site olefin polymerization. significantly enhanced 1-octene and isobutene comonomer enchainment in ethylene polymerizations mediated by binuclear catalysts and cocatalysts," J. Am. Chem. Soc., vol. 125, pp. 10788-10789, 2003. 